\title{
Population genetic structure of Indian oil sardine, Sardinella longiceps along Indian coast
}

\author{
Sandhya Sukumaran *, Wilson Sebastian, A. Gopalakrishnan \\ Central Marine Fisheries Research Institute, Post Box No: 1603, Ernakulam North P.O., Kochi, Kerala, India, Pin-682018
}

\section{A R T I C L E I N F O}

\section{Article history:}

Received 21 August 2015

Received in revised form 13 October 2015

Accepted 13 October 2015

Available online 20 October 2015

\section{Keywords:}

Indian oil sardine Sardinella longiceps

Mismatch analysis

Demographic expansion

Fish genetic stocks

Historical demography

\begin{abstract}
A B S T R A C T
Genetic stock structure and historical demography of Indian oil sardine, a commercially and ecologically important small pelagic fish, was studied using mitochondrial control region and Cytochrome C Oxidase I (COI) sequences. A 758 bp portion of the control region in 287 individuals and a 576 bp portion of the COI gene in 291individuals from 10 locations along the distribution range were amplified resulting in 236 and 84 haplotypes, respectively. The high haplotype and low nucleotide diversity values $(0.99$ and 0.19 for control region and 0.85 and 0.004 for COI, respectively) are characteristic of populations having undergone a demographic expansion. Genetic differentiation, $\Phi_{\mathrm{ST}}$, was low and insignificant between populations using both control region and COI gene markers. Mismatch analysis showed a recent demographic and spatial expansion coinciding with the late Pleistocene epoch. Mantel tests revealed the lack of isolation by distance which is attributable either to high levels of migration overriding the effect of genetic drift or to insufficient time for accomplishing a balance between migration and drift after a recent range expansion.
\end{abstract}

(c) 2015 Elsevier B.V. All rights reserved.

\section{Introduction}

The commercial value of small pelagic fishes (oil sardines and anchovies) is low in export market, but in developing countries, they contribute to a substantial portion of the income from fishing due to their abundance. Indian oil sardine, Sardinella longiceps, is one of the commercially important small pelagic fish forming the largest fishery in India (annual landing 0.6 million tons (CMFRI, Kochi, 2014) and its fishery peaks (50\% of the landings) around the Malabar upwelling zone of the Western Indian Ocean upwelling system. The Western Indian Ocean is one of the strongest upwelling zones among world oceans and the upwelling along these coasts is mainly wind induced occurring during June-August (Bakun et al., 1998). Oceanographic features of the Malabar upwelling zone impart a major influence on the success or failure of sardine recruitment which in turn affects the fishery of that year since the sardine fishery is dominated by 0 and 1-year classes (Devaraj et al., 1997; Krishnakumar and Bhat, 2008). The fishery showed high variability on a decadal scale with periods of abundance and crashes during this century (Longhurst and Wooster, 1990; Xu and Boyce, 2009). Indian oil sardine is a small pelagic fish confined to the continental shelf waters at depths of 20-200 m. The geographic distribution of this species is along the Northern and

Abbreviations: dNTP, deoxyribonucleoside triphosphate; COI, Cytochrome C Oxidase I; CMFRI, Central Marine Fisheries Research Institute; NW, North West; SW, South West; SE, South East.

* Corresponding author

E-mail address: sukumaransandhya@yahoo.com (S. Sukumaran).
Western Indian Ocean; mainly North East, South East, South West, and northwest India, Gulf of Oman, and Gulf of Aden (Whitehead, 1985) (Fig. 1). It is a migratory, schooling species and feeds mainly on phytoplankton and breeds once a year at a size of $14-15 \mathrm{~cm}$ with peak spawning season during August-September along the South West coast of India. Spawning grounds are not yet located for this species. The eggs and larvae are pelagic and pelagic larval duration is approximately 40 days (Kuthalingam, 1960).

The management of small pelagic fishery is met with several challenges like identification of stock units and assessment of these stocks periodically to ensure long-term sustainability. Indian oil sardine is managed as a single stock in India, even though some studies have pointed out the possibility of existence of several subpopulations (Venkita Krishnan, 1993; Mohandas, 1997). Venkita krishnan (1993) used nine enzyme loci to discriminate between subpopulations and concluded that Indian oil sardines from Cochin, Calicut, Mangalore, Mandapam, and Madras (now Chennai) represented discrete genetic stocks representing five subpopulations based on allele frequencies. Similar conclusions (heterogeneity between samples from Cochin, Calicut, Mangalore, and Mandapam) were also made by Mohandas (1997) using cytogenetic, biochemical genetic, and morphometric tools. On the contrary, Menezes (1994)reported low genetic variability in Indian oil sardines from West Coast of India using allozymes. The major limitation of all these studies was very low sample size and geographic coverage. Hence, a major impediment to Indian oil sardine stock assessment and management is the lack of information regarding evolutionary significant units in Indian oil sardine populations along Indian coast. The lack of baseline data related to genetic diversity and 


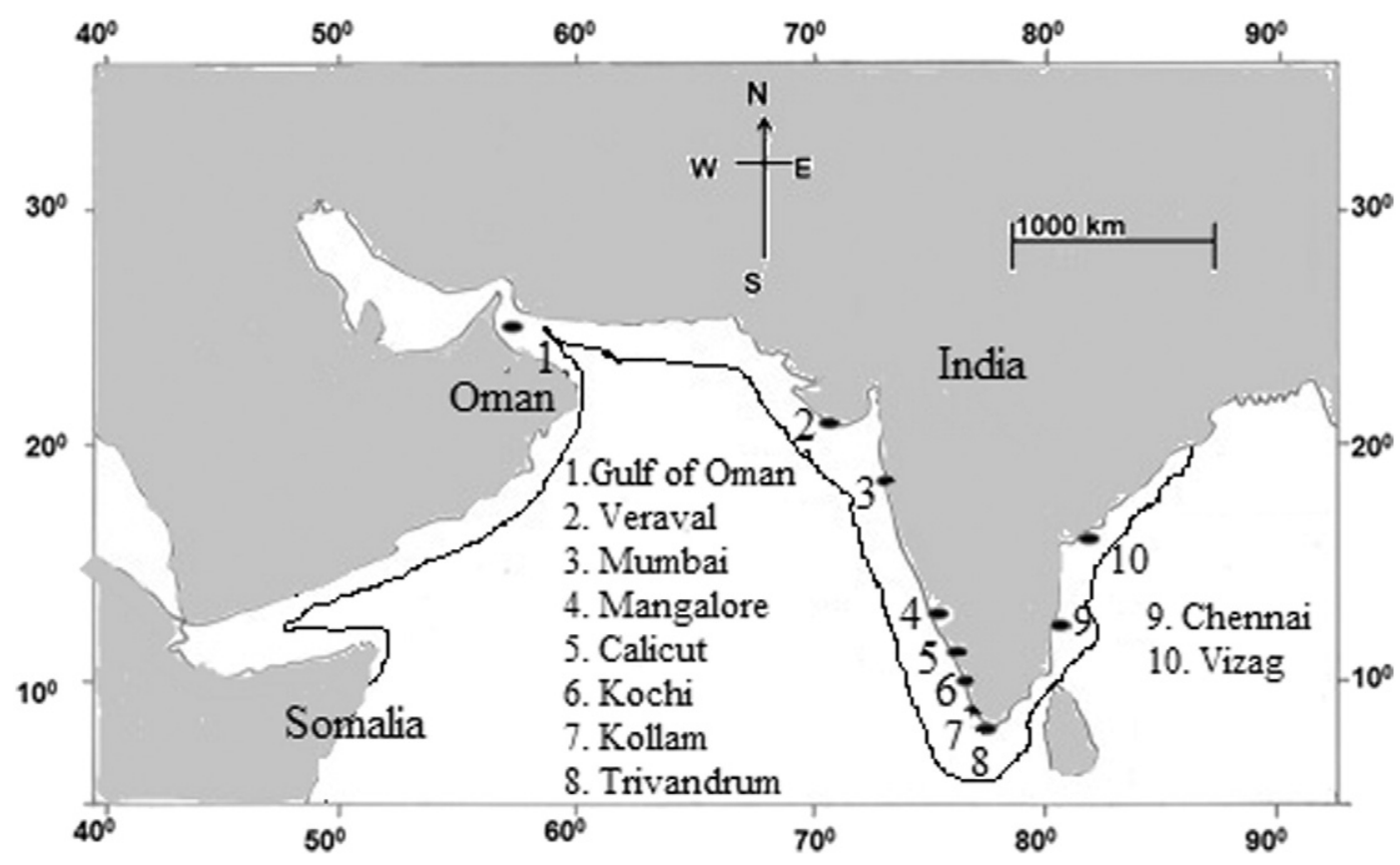

Fig. 1. Map of Indian Ocean region showing the sampling locations. Black continuous line indicates areas of geographic distribution.

divergence in sardine populations also is a constraint in conserving the genetic variation and understanding the dynamics of sardine populations to climate change related warming of the Indian Ocean. Recent investigations on climatic impacts on Indian Ocean fishery have pointed to the possibility of range expansion of Indian oil sardine populations to Northern Indian Ocean habitats due to the increase in sea surface temperature and consequent changes in oceanic circulation patterns (Vivekanandan, 2011).

Historical demography of small pelagic fishes caught from Indian seas has never been studied in detail, which is a major constraint while trying to figure out the influence of past environmental and climatic fluctuations on fish populations. The historical demography and genetic stock structure of small pelagic fishes like sardines and anchovies had been investigated using mitochondrial markers along Atlantic and Pacific coasts (Lecomte et al., 2004; Atarhouch et al., 2006; Li et al., 2012; Diaz-Viloria et al., 2012; Vinas et al., 2013) providing critical insights into their historical behavior.

In the present study, we tested the hypothesis regarding presence of different evolutionary units of Indian oil sardine in Indian waters using two mitochondrial DNA markers; control region and COI gene sequences, by collecting fishes from 10 locations, nine all over the Indian coast (NW, SW, and SE coasts) and one at the Gulf of Oman. Historical demographic information was derived from control regions sequences due to the availability of standard mutational rate values (Donaldson and Wilson, 1999).

\section{Material and methods}

2.1. Sample collection, DNA extraction, and amplification of the two mitochondrial fragments

Samples were collected during 2013 and 2014 from 10 different locations from gill netters and ring seiners (a mini purse seine) operated near the coast; 3 locations along NW coast of India; (Gulf of Oman, Veraval, and Mumbai), 5 locations along SW coast of India (Mangalore, Calicut, Kochi, Kollam, and Trivandrum), and 2 locations along SE coast of India (Chennai and Vizag). Sampling locations are shown in Fig. 1.

Total DNA was extracted from muscle tissue using a standard phenol/chloroform extraction protocol and ethanol precipitation. Universal primers (Cheng et al., 2012; Folmer et al., 1994) were used for amplifying the partial control region and COI gene of Sardinella longiceps. PCR amplifications were carried out in $25 \mu \mathrm{l}$ reaction mixture containing $10 \mathrm{mM}$ Tris- $\mathrm{HCl}, \mathrm{pH} 8.3,50 \mathrm{mM} \mathrm{KCl}, 1.5 \mathrm{mM} \mathrm{MgCl}_{2}, 200 \mu \mathrm{M}$ of each dNTP, $0.2 \mu \mathrm{M}$ of oligonucleotide, 1 unit of Taq DNA polymerase, and $50 \mathrm{ng}$ of template DNA. The PCR reaction was carried out in a Biorad T100 thermocycler (Biorad, USA) programmed for an initial denaturation at $94{ }^{\circ} \mathrm{C}$ for 4 min followed by 35 and 33 cycles of denaturation (for control region and COI, respectively) at $94{ }^{\circ} \mathrm{C}$ for $30 \mathrm{~s}$, annealing at $48{ }^{\circ} \mathrm{C}$ and $42^{\circ} \mathrm{C}$ (for control region COI, respectively) for $30 \mathrm{~s}$, extension at $72^{\circ} \mathrm{C}$ for $55 \mathrm{~s}$ and $40 \mathrm{~s}$ (for control region COI, respectively) and a final extension at $72{ }^{\circ} \mathrm{C}$ for $7 \mathrm{~min}$. Purification of the PCR product was carried out using Qiagen PCR purification kit and sequenced with both primers using the BigDye Terminator Sequencing Ready Reaction v3.0 kit (Applied Biosystems) following instructions of the manufacturer. Sequencing was carried out on an ABI 3730 automated sequencer. A 758 bp region of the control region and a 576 bp region of COI of Sardinella longiceps was amplified in all the sampled individuals for phylogenetic and population genetic analysis. All the partial sequences of Sardinella longiceps control region and COI were deposited in GenBank with the accession numbers (KJ466087-KJ466091; KJ472113KJ472120; KJ888156-KJ888390) (KP000859-KP000897) (KP000898KP001108; КР099426-KР099430) (КТ375357-КТ375431).

\subsection{Population genetic statistics}

Even though both control region and COI genes are from the same mitochondrial DNA, we did not concatenate the sequences since different regions of mitochondrial DNA evolve at different rates (Hauser et al., 2001) and the gamma values and the mutational rate models were different for both sets of the data. Mitochondrial control region is considered as a fast-evolving gene region having rate of evolution two to five times higher than mitochondrial protein coding genes (Hauser et al., 2001), whereas COI is considered as a slow evolving gene region. The sequences of 758 bp from 287 individuals for control region and 576 bp from 291 individuals for COI gene region from all over the Indian coast were aligned using Clustal W in MEGA 5.1. All the gaps (only in control region) were excluded from phylogenetic analyses. The phylogeny was reconstructed with Geneious R7 (Biomatters Ltd., New Zealand) using the neighbor-joining method with 1000 bootstraps (Felsenstein, 1985), and a bootstrap consensus tree was constructed. 
The Akaike information criterion implemented in MEGA 5.1 was used to select the best-fit evolutionary model for the sequences. Arlequin Version 3.5.1.2 (Schneider et al., 2000) and DnaSP 4.0 (Rozas et al., 2003) were used for population genetic analyses. The number of polymorphic sites (S), nucleotide diversity ( $\pi, \mathrm{Nei}, 1987)$, haplotype diversity $\left(H_{d}, N e i, 1987\right)$, average number of pairwise nucleotide differences (K, Tajima, 1983), percentage of private haplotypes, total number of synonymous and non-synonymous mutations in COI region and Transition/Transversion ratios were assessed for each population. Population genetic structure was analyzed using the F-statistics, $\Phi_{\mathrm{ST}}$ (Excoffier et al., 1992) using 20,000 permutations to estimate significance (calculated with Arlequin Version 3.5.1.2, Schneider et al., 2000). The differences among stocks were estimated using analysis of molecular variance (AMOVA) in Arlequin Version 3.5.1.2. The sequence divergence values were estimated using the algorithm of Tamura and Nei (1993) for control region sequences and Kimura 2P (Kimura, 1980) for COI gene sequences. P values were adjusted with sequential Bonferroni correction in all the tests (Rice, 1989). A network of haplotypes was constructed in PopART version 1.7 (http://popart.otago.ac.nz) for both control region and COI haplotypes using median joining networks option (Bandelt et al., 1999).

\subsection{Historical demography}

Demographic analyses were carried out using the mismatch distribution (Rogers and Harpending, 1992; Schneider and Excoffier, 1999) in Arlequin Version 3.5.1.2 (Schneider et al., 2000) and DnaSP 4.0 (Rozas et al., 2003). Mismatch analysis was conducted for the whole population using all the sequences and for each major geographical region separately; North West Indian Ocean region (Oman, Veraval, and Mumbai), South West Indian Ocean region (Mangalore, Calicut, Kochi, Trivandrum), and South East Indian Ocean region (Chennai and Vizag). Population growth and declines will result in marked patterns in the distribution of pairwise nucleotide differences resulting in a unimodal wave in populations which had undergone a sudden population expansion after a bottleneck and a multimodal wave in equilibrium populations (Rogers and Harpending, 1992; Schneider and Excoffier, 1999). The stepwise expansion model (demographic and spatial) was validated using a parametric bootstrapping method which compares the fit with the expected mismatch distribution of the observed and 100 simulated mismatch distributions. The sum of square deviations (SSD) between the observed and simulated distributions and expected distributions indicates the fit to the expected mismatch distribution. Further, Harpending's Raggedness index (Hri; Harpending, 1994) also gives a measure of the smoothness of the observed distribution. Tajima's D (Tajima, 1989) and Fu's Fs (Fu, 1997) statistics were also estimated using DnaSP 4.0 (Rozas et al., 2003). Tajima's D and Fu's Fs test for deviations from neutrality either due to selection, bottleneck, or population expansion. Since mitochondrial DNA markers are considered to be neutral, deviations from neutrality may be due to population expansion. The relationship between genetic differentiation and geographic distance was determined using Mantel test (Mantel, 1967) in XLStat. Genetic distance matrix was represented by (Fst/1-Fst) values and geographic distance matrix was represented by the shortest sea distance (in nautical miles) between all sets of sampling sites.

The estimates of $\tau, \theta_{0}$, and $\theta_{1}$ were also derived using a generalized nonlinear least squares approach (Schneider and Excoffier, 1999) with bootstrap confidence intervals as implemented in Arlequin, Version 3.5.1.2. Estimate of mutational time tau $(\tau)$ can be used to calculate the expansion time $(\mathrm{T})$ with the equation $\mathrm{T}=\tau / 2 \mathrm{u}$ generations (Rogers and Harpending, 1992). The parameter ' $2 u$ ' was estimated with the equation $2 \mathrm{u}=\mu \mathrm{k}$ (Nei and Tajima, 1981) where $\mu$ is the mutation rate which is $1 \times 10^{-7} /$ site/year for the mitochondrial control region of fishes using a strict molecular clock (McMillan and Palumbi, 1997; Ho et al., 2011) with a generation time of 1 year for oil sardine and $\mathrm{k}$ is the number of nucleotides covered in the data (758 bp).
Effective population size was estimated for initial population $\mathrm{N}_{0}$ and expanded population $\mathrm{N}_{1}$ by substituting $\theta_{0}=2 \mathrm{uN}_{0}\left(\mathrm{~N}_{0}=\theta_{0} / 2 \mathrm{u}\right)$ and $\theta_{1}=2 \mathrm{uN}_{1}\left(\mathrm{~N}_{1}=\theta_{1} / 2 \mathrm{u}\right)$ where $2 \mathrm{u}=\mu \mathrm{k}$ is the mutational rate considering a generational time of 1 year for sardines (Devaraj et al., 1997). Control region sequences were only used for deriving these values due to the availability of standardized values for mutational rate.

\section{Results}

\subsection{Population genetics statistics}

The analysis of 758 bp portion of the sardine control region excluding gaps revealed very high levels of variation. A total of 287 individuals were studied from 10 sites producing 236 haplotypes. The most abundant haplotype was recorded in 5 individuals. 209 variable sites consisted of 116 singleton sites and 93 parsimonious informative sites with average value of nucleotide differences being 9.24. Overall haplotype $\left(\mathrm{H}_{\mathrm{d}}\right)$ and nucleotide diversity $(\pi)$ for all sequences were 0.99 and 0.019 , respectively. COI gene region was analyzed for a portion of $576 \mathrm{bp}$ and a total of 84 haplotypes were produced from 291 individuals. The most abundant haplotype was found in 80 individuals. There were 98 variable sites consisting of 46 singleton sites and 52 parsimony informative sites with average value of nucleotide differences being 2.3. Overall haplotype $\left(\mathrm{H}_{\mathrm{d}}\right)$ and nucleotide diversity $(\pi)$ for all sequences were 0.85 and 0.004 respectively. The basic statistics of both sequence sets are presented in Table 1.

The best evolutionary model for nucleotide substitution for the control region data was the Tamura 3-parameter (T92) (Tamura, $1992)$ with invariable sites $(I=0.39)$ and rate heterogeneity $(G=$ 0.30) $(\mathrm{T} 92+\mathrm{G}+\mathrm{I})$ and for COI gene region nucleotide substitution was Kimura $2 p$ with a rate heterogeneity $(G=0.33)(K 2+G)$. The phylogeny did not resolve any subpopulation structure and bootstrap support at major nodes was not significant. The haplotype network based on COI sequences was star-shaped (Fig. 2), indicative of a recent demographic expansion. One haplotype was common to nine geographic regions. The network diagram using control region haplotypes was not informative due the large number of haplotypes and small number of shared haplotypes. Genetic differentiation among sardine populations from different locations was tested using $\Phi_{\text {ST }}$ pairwise comparisons of both control region sequences and COI gene sequences. There were 36 possible comparisons and none of them were statistically significant after Bonferroni correction. A hierarchical AMOVA test was carried out to further confirm these results by partitioning the variance among and within populations, i) one gene pool comparison considering all the populations as a single gene pool, ii) among groups, within groups and within populations: two gene pools [East (Chennai \& Vizag) versus West Coast (Oman, Veraval, Mumbai, Mangalore, Calicut, Kochi, Kollam, and Trivandrum)] and three gene pools (NW, SW, and SE coast populations). The overall levels of genetic differentiation were not significant $(p>0.001)$ in all the analyses with a global $\Phi_{\text {ST }}$ value of 0.011 with control region sequences and 0.005 with $\mathrm{COI}$ gene sequences.

\subsection{Historical demography}

The mismatch distribution of both control region sequences and COI gene sequences showed unimodal pattern when all samples were included (Fig. 3) indicating sudden expansion in population size. The Harpending's raggedness index (control region-0.014; COI-0.08) and $\mathrm{P}_{\mathrm{SSD}}$ values (control region-0.38; COI-0.37) indicated a significant fit of the observed and expected distributions. Deviation from a stable population history was considerable based on significant negative values of Fu's Fs and Tajima's $D$ values $(-16.1$ and -2.35 , respectively, for control region; -11.3 and -2.68 , respectively, for COI sequences). This indicates an excess of low-frequency haplotypes. Region-wide mismatch analysis also showed unimodal patterns for North West and South West Indian regions indicating a sudden expansion in population 
Table 1

Sampling details and sequence characteristics of mitochondrial control region and COI gene.

\begin{tabular}{|c|c|c|c|c|c|c|c|c|c|c|c|c|c|c|}
\hline \multirow[t]{2}{*}{ Location } & \multicolumn{2}{|c|}{ Total no. of samples } & \multicolumn{2}{|c|}{$\begin{array}{l}\text { Total no. } \\
\text { haplotypes }\end{array}$} & \multicolumn{2}{|c|}{$\begin{array}{l}\% \text { of private } \\
\text { haplotypes }\end{array}$} & \multicolumn{2}{|c|}{$\begin{array}{l}\text { Haplotypes } \\
\text { diversity }\end{array}$} & \multicolumn{2}{|c|}{ Nucleotide diversity } & \multicolumn{2}{|c|}{$\begin{array}{l}\text { Total no. } \\
\text { synonymous and } \\
\text { non-synonymous } \\
\text { mutation in } \mathrm{CO} 1\end{array}$} & \multicolumn{2}{|c|}{$\begin{array}{l}\text { Transition/Transversion } \\
\text { ratio }\end{array}$} \\
\hline & $\mathrm{CO} 1$ & $\begin{array}{l}\text { Control } \\
\text { region }\end{array}$ & $\mathrm{CO} 1$ & $\begin{array}{l}\text { Control } \\
\text { region }\end{array}$ & $\mathrm{CO} 1$ & $\begin{array}{l}\text { Control } \\
\text { region }\end{array}$ & $\mathrm{CO} 1$ & $\begin{array}{l}\text { Control } \\
\text { region }\end{array}$ & $\mathrm{CO} 1$ & $\begin{array}{l}\text { Control } \\
\text { region }\end{array}$ & Syn & Non-syn & Control region & $\mathrm{CO} 1$ \\
\hline $\begin{array}{l}\text { North West } \\
\text { India }\end{array}$ & $(\mathrm{N}=84)$ & $(\mathrm{N}=72)$ & & & & & & & & & & & & \\
\hline Gulf of Oman & 25 & 22 & 10 & 21 & 30 & 100 & 0.721 & 0.995 & 0.00230 & 0.0502 & 3 & 18 & 5.18 & 3 \\
\hline Veraval & 31 & 20 & 9 & 18 & 50 & 100 & 0.800 & 0.989 & 0.00173 & 0.0422 & 2 & 17 & 4.31 & 3 \\
\hline Mumbai & 28 & 30 & 9 & 28 & 77 & 100 & 0.878 & 0.995 & 0.00389 & 0.0391 & 1 & 24 & 5.31 & 7.33 \\
\hline $\begin{array}{l}\text { South West } \\
\text { India }\end{array}$ & $(\mathrm{N}=151)$ & $(\mathrm{N}=160)$ & & & & & & & & & & & & \\
\hline Mangalore & 30 & 36 & 10 & 34 & 70 & 97 & 0.910 & 0.998 & 0.00381 & 0.0414 & 3 & 23 & 2.27 & 3.33 \\
\hline Calicut & 39 & 38 & 5 & 23 & 40 & 100 & 0.772 & 0.992 & 0.00305 & 0.0583 & 0 & 14 & 1.63 & 2.5 \\
\hline Kochi & 30 & 30 & 9 & 24 & 50 & 96 & 0.781 & 0.990 & 0.00250 & 0.0452 & 1 & 17 & 3.29 & 8 \\
\hline Kollam & 25 & 27 & 5 & 23 & 40 & 100 & 0.756 & 0.998 & 0.00423 & 0.0380 & 2 & 16 & 4.75 & 2.5 \\
\hline Trivandrum & 27 & 29 & 5 & 22 & 66 & 96 & 0.732 & 0.995 & 0.00371 & 0.0426 & 2 & 21 & 4.31 & 3.6 \\
\hline $\begin{array}{l}\text { South East } \\
\text { India }\end{array}$ & $(\mathrm{N}=56)$ & $(\mathrm{N}=55)$ & & & & & & & & & & & & \\
\hline Chennai & 27 & 30 & 10 & 22 & 90 & 92 & 0.949 & 0.995 & 0.00676 & 0.0425 & 2 & 37 & 2.81 & 1.43 \\
\hline Vizag & 29 & 25 & 12 & 21 & 50 & 95 & 0.958 & 0.986 & 0.00549 & 0.0432 & 0 & 16 & 1.79 & 2 \\
\hline
\end{tabular}

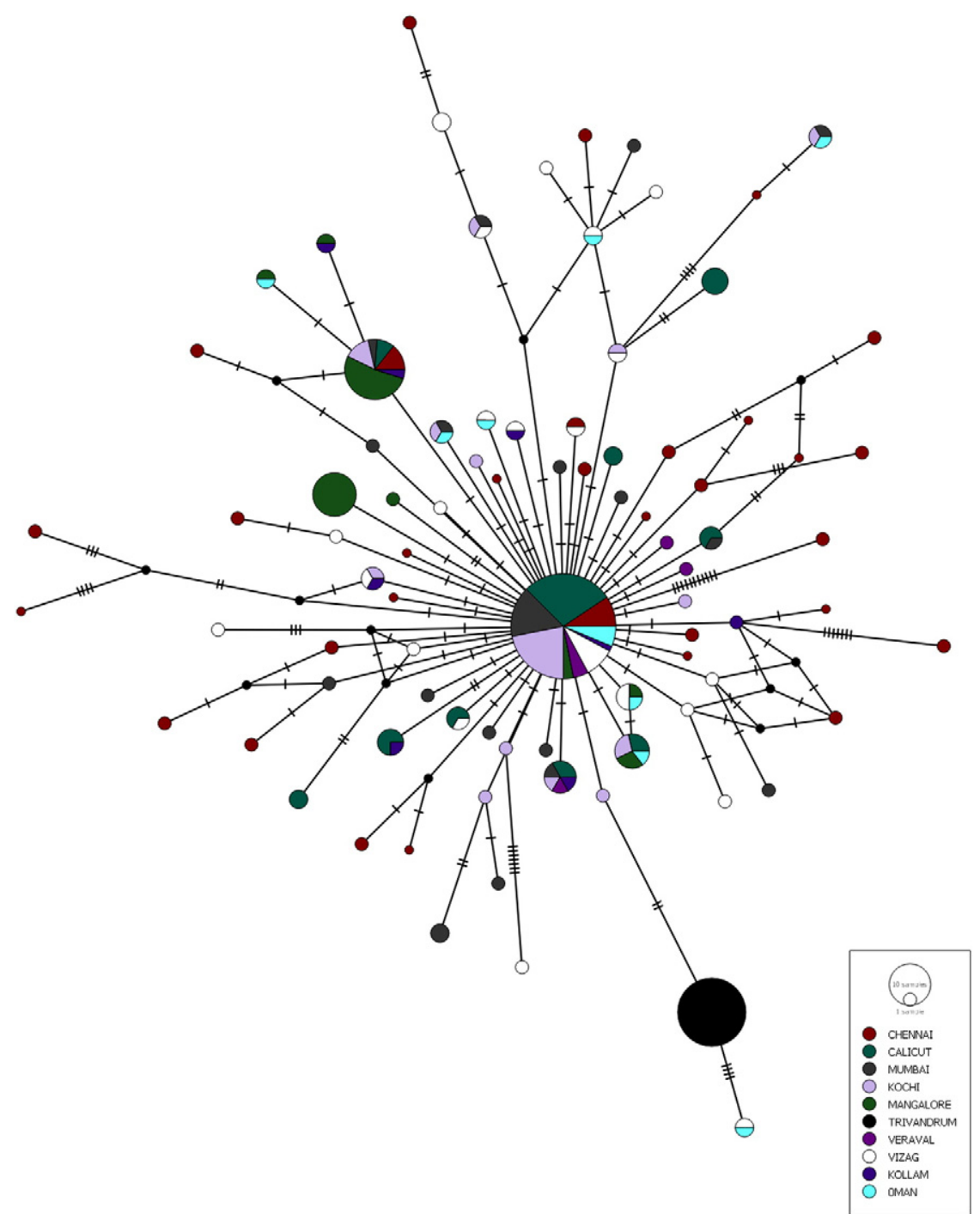

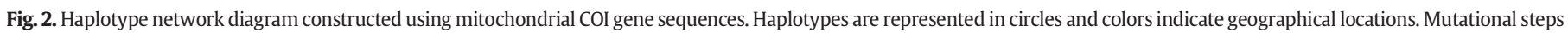
are indicated in vertical stripes. 
a)
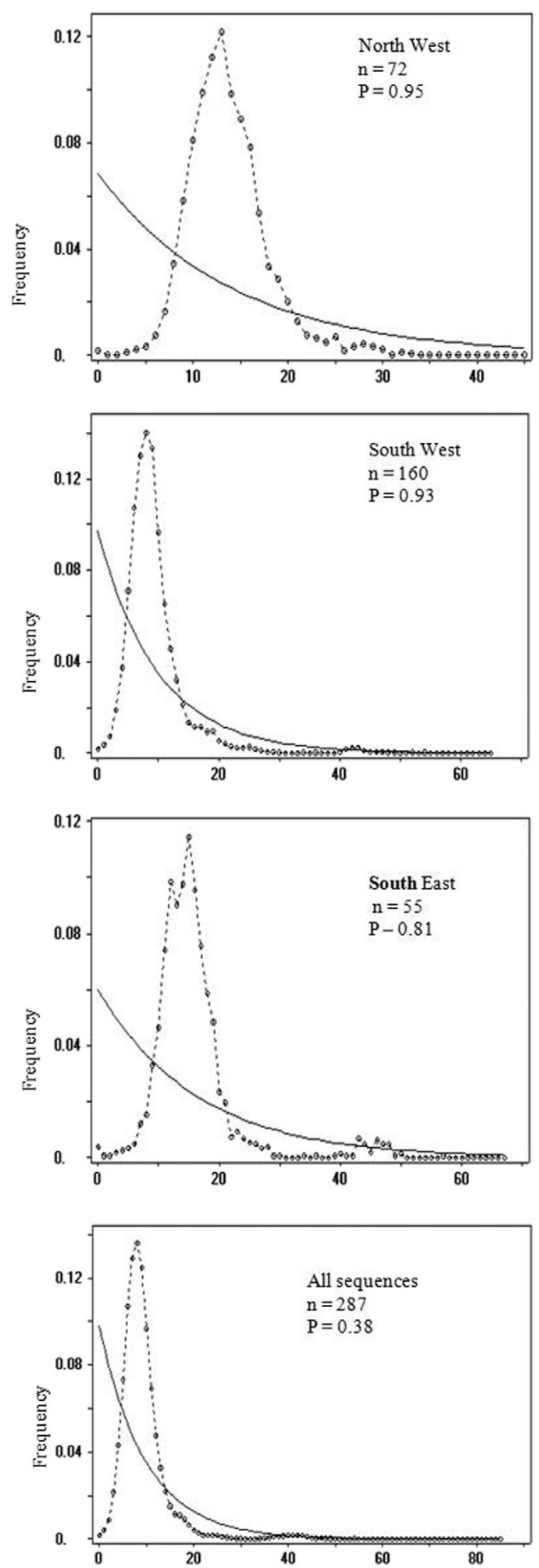

No: of pairwise differences: Sardinella longiceps b)
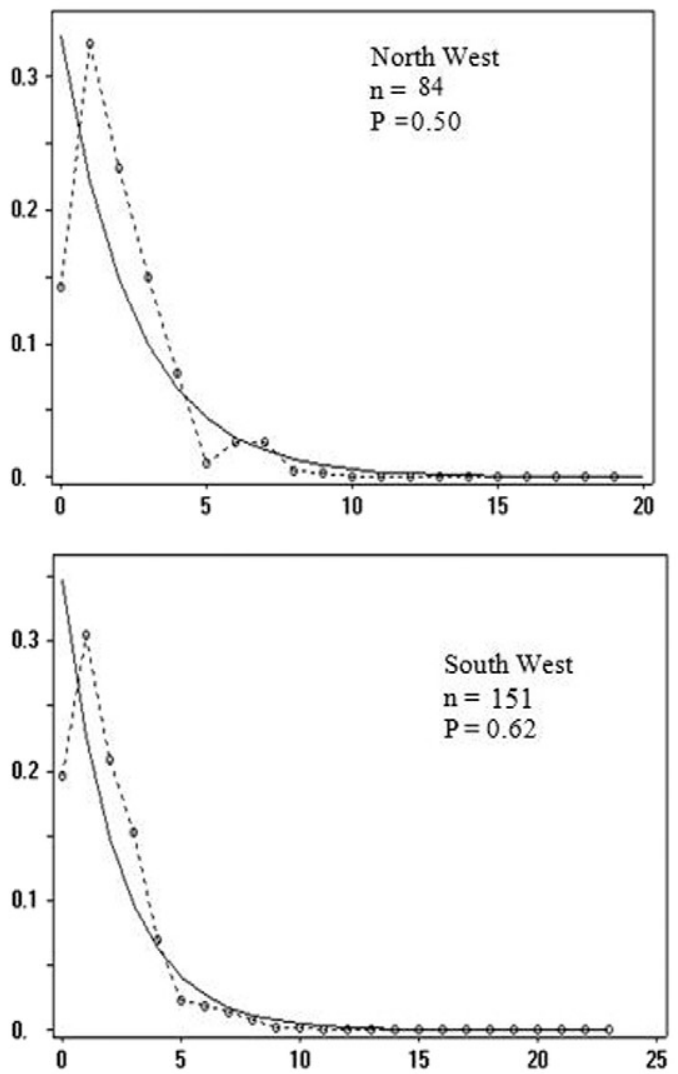

expected observed
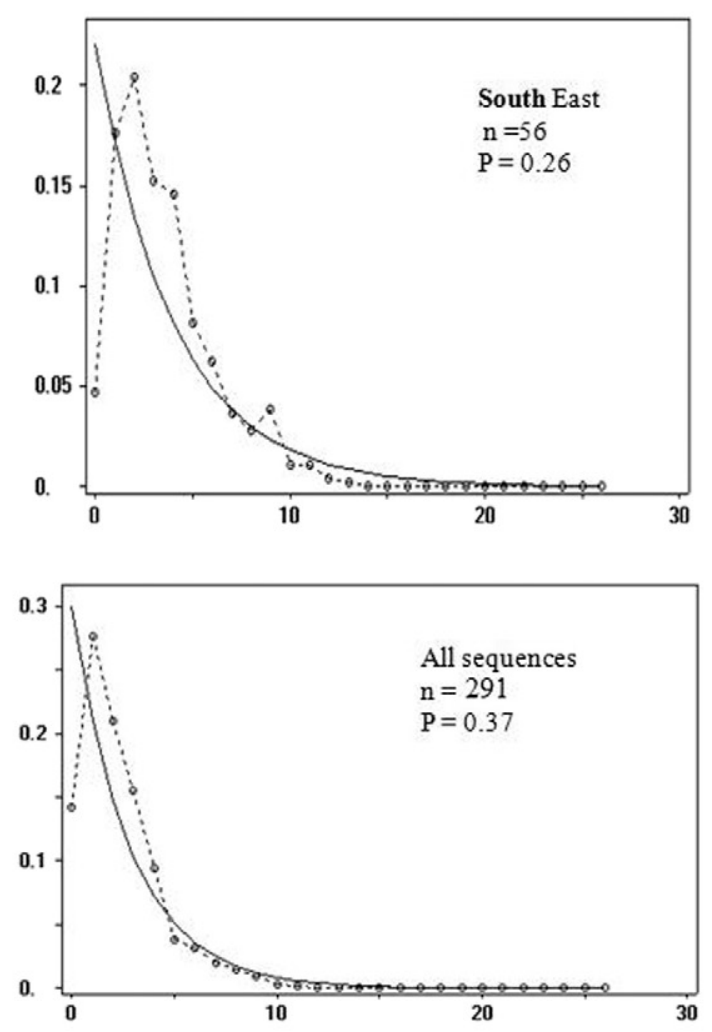

No: of pairwise differences: Sardinella longiceps

Fig. 3. Mismatch distribution for Sardinella longiceps for different geographical regions and for the whole population: a) control region sequences, b) COI gene sequences. 
size (Fig. 3). A bimodal pattern was present in South East Indian Ocean region even though the $\mathrm{P}$ values of raggedness index were not significant. Both demographic and spatial expansion models were validated and the time since expansion for demographic and spatial expansion for the entire population was between $0.95 \times 10^{5}$ years before present and $0.94 \times 10^{5}$ years before present. So spatial expansion has taken place during the time of demographic expansion. Effective female population size before demographic expansion ranged from zero (founder events) to 30,000 and after demographic expansion ranged from $1.1 \times 10^{6}$ to $1.31 \times 10^{9}$ at different locations. Migration rate during spatial expansion ranged from 68 to 4033 individuals with the highest migration (4033) recorded at Mangalore. Molecular diversity values $\left(\theta_{\mathrm{H},}, \theta_{\mathrm{S}}, \theta \pi\right.$ and $\left.\theta_{\mathrm{K}}\right)$ were higher in Mangalore for control region sequences and at Vizag for COI gene sequences. There was no geographical restriction in haplotypes as shared haplotypes were present in all the locations, and this pattern may be indicative of a range expansion. The results of the mantel test with both sequence sets revealed lack of a significant correlation $(\mathrm{P}>0.05)$ between $\mathrm{F}_{\mathrm{ST}} /\left(1-\mathrm{F}_{\mathrm{ST}}\right)$ and geographic distance, and thus there was no evidence of isolation by distance.

\section{Discussion}

There was no evidence of significant population structuring in Indian oil sardine populations when the whole set of sequences of both control region (fast evolving gene region) and COI gene sequences (slow evolving gene region) were used. The population expansion of sardine populations probably took place during $0.95 \times 10^{5}$ years before present which corresponds to late Pleistocene epoch characterized by frequent El Nino events and influx of warm waters into the Indian Ocean. This period also corresponds to a significant spatial or range expansion since mismatch parameters of spatial expansion showed similar time estimates as demographic expansion ( $0.94 \times 10^{5}$ years before present). The star like haplotype network (using COI genes sequences) and high values of haplotype diversity coupled with low values of nucleotide diversity (with both sets of sequences) are also indicative of a recent demographic and range expansion after a period of low effective population size (Slatkin and Hudson, 1991; Grant and Bowen, 1998).

The resolving power of mitochondrial gene markers are presumed to be low compared to nuclear gene markers like microsatellites due to its maternal inheritance and in marine pelagic fishes with large effective population sizes (in this case, Indian oil sardine) mitochondrial markers may not be sensitive enough to detect signals of population structure (Hauser and Ward, 1998; Hauser et al., 2001). High haplotype diversity coupled with low nucleotide diversity indicates the presence of many private and closely related haplotypes, and hence conventional $\Phi_{\mathrm{ST}}$ analysis using haplotype frequency and distance between haplotypes may not represent the true picture. These results point to the need for studies on Indian oil sardine populations using advanced markers with high resolving power like microsatellites, nuclear gene markers, or next-generation methods like SNP genotyping of neutral and functional gene regions to better understand any other hidden and low genetic differentiation between populations. The results of the mantel test revealed the lack of isolation by distance and this pattern is prominent when migration is so high that it overcomes the effect of genetic drift (Slatkin, 1993; Liu et al., 2006) or when there is inadequate time for achieving a balance between migration and drift after a recent range expansion and contraction (Slatkin, 1993). This may also indicate the influence of currents or other factors in controlling dispersal as the complexity of oceanographic parameters makes it impossible to decouple dispersal distance from geographic distance (Selkoe and Toonen, 2011).

Evidence from molecular data shows that a demographic expansion of Indian oil sardine had taken place $0.95 \times 10^{5}$ years before present during the late Pleistocene epoch along with a spatial/range expansion. Pleistocene epoch was characterized by sudden climatic shifts from one state to the other and repeated glaciations (Sinha and Singh, 2007). The late Pleistocene was a period of intense upwelling in the Indian Ocean (Sinha and Singh, 2007) due to a weakening of the Leeuwin current and a reduced Indonesian through flow which would have increased the productivity along the Indian coast triggering a demographic as well as spatial expansion of Indian oil sardine populations. The signals of these range expansion were also evident in region-wide mismatch analysis especially in North West and South West Indian regions. In South East Indian regions, the distributions tended to be bimodal, which may be due to a colonization event consisting of random haplotype lineages (Lecomte et al., 2004). Mitochondrial DNA genealogies of temperate water sardines (Sardinops and Sardina) have been studied and discussed in relation to oceanographic processes and the patterns showed shallow population genetic structure which is attributed mainly to periodic extinctions and recolonizations in response to variations in oceanographic parameters like sea surface temperature, upwelling intensities, current patterns, and retention eddies (Grant and Bowen, 1998). Tropical Sardinella species (Sardinella longiceps) in the present study also showed similar patterns of shallow genetic structure in mtDNA with high haplotype and low nucleotide diversities. The expansion time of temperate sardine Sardina pilchardus has been estimated using control region sequences as between 0.54 and $1.64 \times 10^{5}$ years before present when calculated using a range of mutational rates $\left(1.1 \times 10^{-7} /\right.$ site/year to $3.6 \times 10^{-8} /$ site/year) (Atarhouch et al., 2006), and this period also corresponds to the late Pleistocene. Population expansion time has been estimated in Pacific sardine, Sardinops sagax from California coast using cytochrome b sequences as $2.3 \times 10^{5}$ years before present using a calibration of $2 \%$ sequence divergence per million years (Lecomte et al., 2004) and the reasons for sudden expansion were attributed to return of upwelling events in the Pleistocene after the glaciations events. However, the use and accuracy of molecular clock calibration has been questioned recently due to the time dependence of rates as short-term mutation rate is higher than long-term substitution rates and disparities have been observed in several taxa when estimates of divergence time were made using molecular clock and paleontological evidence (Ho et al., 2011). While, an estimate of $1 \times 10^{-7} /$ site/year has been giving unbiased estimates of the substitution rate independent of population size when simulations were carried out using Bayesian method (Ho et al., 2011) and we have used this rate in the present study.

Indian oil sardine is considered to be an abundant species and risks of extinction are thought to be very low. But the variability in recruitment and periodic extinctions and recolonizations may make the species vulnerable to overfishing. Further studies should be focused on identifying different spawning cohorts or contingents with different behavioral characteristics in space and time so that large variations in recruitment, natal homing, or other selection processes acting on uncertain habitats can be revealed. Highly evolving nuclear DNA markers like microsatellites can also be used to identify any hidden variations and stock structure in Indian oil sardine populations.

\section{Conflict of interest statement}

None to declare.

\section{Acknowledgements}

The study was funded by Indian Council of Agricultural Research (ICAR), India. The authors like to place on record their sincere gratitude to the Director, CMFRI, for all the encouragements and support. We would also like to thank the anonymous reviewers for their constructive suggestions to improve the quality of the manuscript. 


\section{References}

Atarhouch, T., Ruber, L., Gonzalez, E.G., Albert, E.M., Rami, M., Dakkak, A., Zardoya, R. 2006. Signature of an early genetic bottleneck in a population of Moroccan sardines (Sardina pilchardus). Mol. Phylogenet. Evol. 39, 373-383.

Bakun, A., Roy, C., Lluch-Cota, S., 1998. Coastal upwelling and other processes regulating ecosystem productivity and fish production in the western Indian ocean. In: Sherman, K., Okemwa, E., Nitiba, M. (Eds.), Large marine ecosystems of the Indian Ocean: Assessment, sustainability and management. Blackwell Sciences Inc., Malden, Massachusettes, pp. 103-141.

Bandelt, H.J., Forster, P., Röhl, A., 1999. Median-joining networks for inferring intraspecific phylogenies. Mol. Biol. Evol. 16 (1), 37-48.

Cheng, Y.Z., Xu, T.J., Jin, X.X., Tang, D., Wei, T., Sun, Y.Y., Meng, F.Q., Shi, G., Wang, R.X. 2012. Universal primers for amplification of the complete mitochondrial control region in marine fish species. Mol. Biol. 46 (5), 727-730.

CMFRI, Kochi, 2014. CMFRI Annual Report 2013-2014. CMFRI, Kochi, p. 279.

Devaraj, M., Kurup, K.N., Pillai, N.G.K., Balan, K., Vivekanandan, E., Sathiadas, R., 1997. Status, prospects and management of small pelagic fisheries of India. In: Devaraj, M., Martosubroto, P. (Eds.), Small pelagic resources and their fisheries in the Asia-Pacific Region. Proceedings of APFIC working party on Marine Fisheries. RAP Publishers, Thailand, p. 445.

Diaz-Viloria, N., Sanchez-Velasco, L., Perez-Enriquez, R., 2012. Recent population expansion in the evolutionary history of the Californian anchovy Engraulis mordax. Hidrobiologica 22 (3), 258-266.

Donaldson, K.A., Wilson Jr., R.R., 1999. Amphi-Panamic geminates of Snook (Perdei: Centropomidae) provide a calibration of the divergence rate in the mitochondrial DNA control region of fishes. Mol. Phylogenet. Evol. 13 (1), 208-213.

Excoffier, L., Smouse, P.E., Quattro, J.M., 1992. Analysis of molecular variance inferred from metric distances among DNA haplotypes: application to human mitochondrial DNA restriction data. Genetics $13,479-491$.

Felsenstein, J., 1985. Confidence limits on phylogenies: an approach using the bootstrap. Evolution 39 (4), 783-791.

Folmer, O., Black, M., Hoeh, W., Lutz, R., Vrijenhoek, R., 1994. DNA primers for amplification of mitochondrial cytochrome c oxidase subunit I from diverse metazoan invertebrates. Mol. Mar. Biol. Biotechnol. 3 (5), 294-299.

Fu, Y.X., 1997. Statistical tests of neutrality of mutations against population growth, hitchhiking and background selection. Genetics 147, 915-925.

Grant, W.S., Bowen, B.W., 1998. Shallow population histories in deep evolutionary lineages of marine fishes: insights from sardines and anchovies and lessons for conservation. J. Hered. 89 (5), 415-426.

Harpending, R.C., 1994. Signature of ancient population growth in a low-resolution mitochondrial DNA mismatch distribution. Hum. Biol. 66, 591-600.

Hauser, L., Ward, R.D., 1998. Population identification in pelagic fish: the limits of molecular markers. In: Carvalho, G. (Ed.), Advances in Molecular Ecology. IOS Press, Amsterdam, pp. 191-224.

Hauser, L., Turan, C., Carvalho, G.R., 2001. Haplotype frequency distribution and discriminatory power of two mtDNA fragments in a marine pelagic teleost (Atlantic herring, Clupea harengus). Heredity 87, 621-630.

Ho, S.Y., Lanfear, R., Bromham, L., Phillips, M.J., Soubrier, J., Rodrigos, A.G., Cooper, A., 2011. Time-dependent rates of molecular evolution. Mol. Ecol. 20, 3087-3101.

Kimura, M., 1980. A simple method for estimating evolutionary rates of base substitutions through comparative studies of nucleotide sequences. J. Mol. Evol. 16, 111-120.

Krishnakumar, P.K., Bhat, G.S., 2008. Seasonal and interannual variations of oceanographic conditions off Mangalore coast (Karnataka, India) in the Malabar upwelling system during 1995-2004 and their influences on the pelagic fishery. Fish. Oceanogr. 17 (1), 45-60.

Kuthalingam, M.D.K., 1960. Observations on the life history and feeding habits of the Indian sardine, Sardinella longiceps. Treubia 25, 207-213.

Lecomte, F., Grant, W.S., Dodson, J.J., Rodriguez-Sanchez, R., Bowen, B.W., 2004. Living with uncertainty: genetic imprints of climate shifts in east pacific anchovy (Engraulis mordax) and sardine (Sardinops sagax). Mol. Ecol. 13, 2169-2182.

Li, H.Y., Xu, T.J., Cheng, Y.Z., Sun, D.Q., Wang, R.X., 2012. Genetic diversity of Setipinna taty (Engraulidae) populations from the China Sea based on mitochondrial DNA control region sequences. Genet. Mol. Res. 11 (2), 1230-1237.
Liu, J.X., Gao, T.X., Yokogawa, K., Zhang, Y.P., 2006. Differential population structuring and demographic history of two closely related fish species, Japanese sea bass (Lateolabrax japonicus) and spotted sea bass (Lateolabrax maculatus) in Northwestern Pacific. Mol. Phylogenet. Evol. 39, 799-811.

Longhurst, A.R., Wooster, W.S., 1990. Abundance of oil sardine (Sardinella longiceps) and upwelling on the southwest coast of India. Can. J. Fish. Aquat. Sci. 47, 2407-2419.

Mantel, N., 1967. The detection of disease clustering and a generalized regression approach. Cancer Res. 27, 209-220.

McMillan, W.O., Palumbi, S.R., 1997. Rapid rate of control region evolution in Pacific butterflyfishes (Chaetodontidae). J. Mol. Evol. 45, 473-484.

Menezes, M.R., 1994. Little genetic variation in the oil sardine, Sardinella longiceps Val., from the western coast of India. Aust. J. Mar. Freshw. Res. 45 (2), 257-264.

Mohandas, N.N., 1997. Population genetic studies on the oil sardine (Sardinella longiceps) $\mathrm{PhD}$ thesis, Cochin University of Science and Technology. Kochi, India, p. 130.

Nei, M., 1987. Molecular Evolutionary Genetics. Columbia University Press, NewYork, p. 512.

Nei, M., Tajima, F., 1981. DNA polymorphism detectable by restriction endonucleases Genetics 97 (1), 145-163.

Rice, W.R., 1989. Analyzing tables of statistical tests. Evolution 43, 223-225.

Rogers, A.R., Harpending, H., 1992. Population growth makes waves in the distribution of pairwise genetic differences. Mol. Biol. Evol. 9, 552-569.

Rozas, J., Sanchez-DelBarrio, J.C., Messeguer, X., Rozas, R., 2003. DnaSP, DNA polymorphism analysis by the coalescent and other methods. Bioinformatics 19, 2496-2497.

Schneider, S., Excoffier, L., 1999. Estimation of past demographic parameters from the distribution of pairwise differences when the mutation rates vary among sites: application to human mitochondrial DNA. Genetics 152 (3), 1079-1089.

Schneider, S., Roessli, D., Excoffier, L., 2000. Arlequin version 2.000: a software for population genetics data analysis. Genetics and Biometry Laboratory. University of Geneva, Geneva.

Selkoe, K.A., Toonen, R.J., 2011. Marine connectivity: a new look at pelagic larval duration and genetic metrics of dispersal. Mar. Ecol. Prog. Ser. 436, 291-305.

Sinha, D.K., Singh, A.K., 2007. Surface circulation in the eastern Indian ocean during last 5 million years: planktic foraminiferal evidences. Indian J. Mar. Sci. 35 (3), 342-350.

Slatkin, M., 1993. Isolation by distance in equilibrium and non-equilibrium populations. Evolution 47, 264-279.

Slatkin, M., Hudson, R.R., 1991. Pair-wise comparisons of mitochondrial DNA sequences in stable and exponentially growing populations. Genetics $129,555-562$.

Tajima, F., 1983. Evolutionary relationship of DNA sequences in finite populations. Genetics $105,437-460$.

Tajima, F., 1989. Statistical methods for testing the neutral mutation hypothesis by DNA polymorphism. Genetics $123,585-595$.

Tamura, K., 1992. Estimation of the number of nucleotide substitutions when there are strong transition-transversion and G + C content biases. Mol. Biol. Evol. 9 (4), 678-687.

Tamura, K., Nei, M., 1993. Estimation of the number of nucleotide substitutions in the control region of mitochondrial DNA in humans and chimpanzees. Mol. Biol. Evol. $10,512-526$.

Venkita Krishnan, P., 1993. Biochemical genetic studies on the oil sardine, Sardinella longiceps (cuvier and valenciennes, 1847) from selected centres of the west coast of India. PhD thesis, Cochin University of Science and Technology. Kochi, India, p. 143.

Vinas, J., Sanz, N., Penarrubia, L., Araguas, R.M., Garcia-Marin, J.L., Roldan, M.I., Pla, C., 2013. Genetic population structure of European anchovy in the Mediterranean sea and the Northeast Atlantic ocean using sequence analysis of the mitochondrial DNA control region. ICES J. Mar. Sci. 71 (2), 391-397.

Vivekanandan, E., 2011. Climate change and Indian marine fisheries. Marine Fisheries Policy Brief-3CMFRI Special publication No 105. Kochi, p. 105.

Whitehead, P.J.P., 1985. Clupeoid fishes of the world. An annotated and illustrated catalogue of the herrings, sardines, pilchards, sprats, anchovies and wolf-herrings. Part 1 - Chirocentridae, Clupeidae and Pristigasteridae. FAO Fish. Synop 125 (7), 303.

Xu, C., Boyce, M.S., 2009. Oil sardine (Sardinella longiceps) off the Malabar coast: density dependence and environmental effects. Fish. Oceanogr. 18 (5), 359-370. 